\title{
Calcium requirements from dairy foods in France can be met at low energy and monetary cost
}

\author{
Adam Drewnowski ${ }^{1 *}$, Wesley Tang ${ }^{1}$ and Rémi Brazeilles ${ }^{2}$ \\ ${ }^{1}$ Center for Public Health Nutrition, University of Washington, Box 353410 Seattle, WA 98195-3410, USA \\ ${ }^{2}$ ITEM STATS, 192 Avenue Charles de Gaulle, 92200 Neuilly-sur-Seine, France \\ (Submitted 17 March 2015 - Final revision received 12 August 2015 - Accepted 21 August 2015-First published online 9 October 2015)
}

\begin{abstract}
Inadequate $\mathrm{Ca}$ intakes are a concern for global public health. In France, most dietary Ca is provided by dairy products: milks, fermented milks (mostly yogurts), dairy desserts and cheeses. The present dairy database ( $n$ 837) included milks ( $n$ 101), fermented milks, yogurts and other fresh dairy products $(n 326)$, desserts $(n$ 162) and a wide variety of cheeses ( $n$ 248). Energy and nutrient values were obtained from industry sources and the French national nutrient composition database. Retail prices were from Paris supermarkets. Products in each group were aggregated into twenty-one categories using clustering analyses. The costs in energy ( $\mathrm{kJ}(\mathrm{kcal})$ ), euros (€), and in SFA, added sugar and Na (defined here as nutrients to LIMit) associated with providing $120 \mathrm{mg}$ of $\mathrm{Ca}$ (equivalent to $15 \%$ daily value (15\% DV)) were calculated for each product group and category. The milk group supplied Ca at the lowest energy, monetary and LIM cost. Fresh plain and 'light' yogurts and fermented milks were next, followed by sweetened yogurts and flavoured milks. Light dairy desserts provided Ca with relatively few energy but were more expensive. Cheeses were a heterogeneous group. Hard cheeses (Comté) provided the most Ca per serving. Semi-hard cheeses (Camembert) and cream and blue cheeses (Roquefort) provided Ca at a cost comparable with sweetened yogurts and flavoured milks. Double cream, soft and goat cheeses were not optimal Ca sources. New value metrics can help identify affordable dairy foods that provide Ca without excessive energy or nutrients to limit. These conditions were satisfied by a wide variety of dairy products in France.
\end{abstract}

Key words: Dairy products: Calcium requirement: Energy: SFA: Sodium: Added sugar: Economics

Dietary guidelines in the USA and in France have stressed the important contribution of milk and milk products to a healthy diet $^{(1,2)}$. Milk, yogurt and cheese are the principal dietary sources of $\mathrm{Ca}$ and vitamin $\mathrm{D}$, identified as nutrients of concern in both French and American diets ${ }^{(1,3)}$. A diversified source of bonebuilding 'lactonutrients', dairy products contribute important amounts of high-quality protein, $\mathrm{P}$ and $\mathrm{K}^{(3-7)}$. On the basis of modelled food patterns, the US and French dietary guidelines for Ca cannot be met in the absence of milk or dairy products ${ }^{(8)}$.

On the basis of analyses of dietary patterns, milk and dairy products have been classified as nutrient-rich foods (NRF), supplying substantially more nutrients than energy to the total $\operatorname{diet}^{(7,9)}$. However, milk and milk products also contain naturally occurring SFA and $\mathrm{Na}$ and can contain added $\mathrm{Na}$ or added sugars. Although some dairy products are of low energy density, others can be high in energy per $100 \mathrm{~g}$ or per serving. Nutrient profiling models have balanced beneficial nutrients against nutrients to limit to arrive at overall scores of nutritional value. Both the SAIN,LIM ${ }^{(10)}$ and the NRF indices ${ }^{(9,11,12)}$ used the foods' content of SFA, added sugar and $\mathrm{Na}$ to create a composite score of nutrients to limit (LIM).
European regulations require that a product contain $>15 \%$ daily value (DV) of a given nutrient per reference amount to be considered a 'good' source of that nutrient. Given that the reference daily value for $\mathrm{Ca}$ in France is $800 \mathrm{mg}, 15 \% \mathrm{DV}$ translates into $120 \mathrm{mg}$ of $\mathrm{Ca}$. We therefore calculated the amounts of energy ( $\mathrm{kJ}(\mathrm{kcal}))$, LIM scores and monetary costs (€) associated with the provision of $120 \mathrm{mg}$ of $\mathrm{Ca}$ by a wide variety of milks and dairy product. The goal was to identify those categories of dairy products that provided $120 \mathrm{mg}$ $\mathrm{Ca}$ at low cost, while minimising energy, $\mathrm{Na}$, added sugars and SFA.

The present approach built on previously published value metrics estimating nutrients per unit cost ${ }^{(13,14)}$. The Affordable Nutrition Index ${ }^{(15)}$ and other measures, based on national food prices in the USA, were intended to identify those food groups and individual foods that were nutrient rich, had low energy density and were affordable. One such study ${ }^{(14)}$, applied to school lunch programmes in the USA, showed that potatoes and beans provided most nutrients per penny. The present metrics extended this approach to the study of dietary $\mathrm{Ca}$, provided by a range of dairy products in France.

Abbreviations: DV, daily value; NRF, nutrient-rich foods

* Corresponding author: A. Drewnowski, fax +1 206685 1696, email adamdrew@uw.edu 


\section{Methods}

\section{Dairy products database}

The dairy products database ( $n$ 837) was created to represent different types of milks, yogurts and cheeses in the French food supply. Data on patterns of dairy consumption in France were obtained from the National Milk Industry Interprofessional Center $^{(16)}$. These data were based on the Kantar consumer panel (available on the French National Interprofessional Center for the Dairy Economy (Centre National Interprofessionnel de l'Économie Laitière) (CNIEL) website) and on consumption data obtained from the Association of Milk Processors ${ }^{(17)}$. The 837 milks and dairy products were divided into four major groups, following industry standards. The first group ( $n$ 101) was fluid milks (whole, low fat, skimmed and flavoured). The second group was fermented milks, including plain, flavoured and 'light' yogurts and yogurts with fruit ( $n$ 326). The third group was Greek yogurts, dairy desserts and dessert creams ( $n$ 162). The very heterogeneous cheese category ( $n$ 248) included soft and hard cheeses, blue cheeses, cream cheeses and processed and low-fat cheeses. Cluster analyses, conducted within each of the four major groups, served to create twentyone product categories.

\section{Nutrient composition database}

Energy and nutrient composition data for the 837 milk and dairy products were obtained from multiple sources, including the product label and the publicly available French nutrient composition database (CIQUAL 2012) maintained by the French Agency for Food, Environmental, and Occupational Health and Safety ${ }^{(18)}$. Additional information was obtained from vendors, company websites and from CNIEL ${ }^{(19)}$. Data were obtained for energy, $\mathrm{Ca}$, SFA, total sugars and $\mathrm{Na}$. Added sugars in yogurts and in flavoured milks were estimated on the basis of data for total sugars and lactose in milk in the CIQUAL nutrient composition table ${ }^{(18)}$. Plain fluid milks, plain yogurts and most cheeses do not contain added sugars. Nutrient composition of food was expressed per $100 \mathrm{~g}$ of edible portion.

\section{Serving sizes}

To calculate Ca content by serving size, we used serving sizes corresponding to the manufacturers' recommendations for fluid milk (200 ml), fermented milks (yogurts) (125 g), dairy desserts $(125 \mathrm{~g})$ and cheeses $(30 \mathrm{~g})$. For comparison purposes, the Reference Amounts Customarily Consumed used by the US Food and Drug Administration for labelling and regulatory purposes are set at $240 \mathrm{ml}$ for fluid milk, $225 \mathrm{~g}$ for yogurt, about $100 \mathrm{~g}$ for ice cream (half cup equivalent) and $30 \mathrm{~g}$ for most cheeses $^{(20)}$.

\section{Retail prices for milk and dairy products}

To establish nutrient composition and retail price of branded items, fresh dairy products (all types and all brands) were systematically purchased from six Paris supermarkets in 2013 (Carrefour, Auchan, E.Leclerc, Système U, lntermarché and
Cora). Data for fluid milks were obtained from three large supermarkets (Carrefour, Auchan and E.Leclerc) and data for cheeses from Auchan and E.Leclerc. For national brands such as Danone, retail prices were obtained from company websites. The pricing of foods followed consistent rules, with prices based on the most-common packaging. For example, yogurts in France are sold in units of four, whereas 'Petits Suisse' fresh cheese is sold in units of twelve. All prices were converted to $100 \mathrm{~g}$. The cost vector (euros/100 g) was then added to the nutrient composition database.

\section{The LIMiting nutrients score}

Reference values for SFA, added sugars and $\mathrm{Na}$ - also based on French standards ${ }^{(21)}$ - were used to create the LIM nutrient density score, a part of the SAIN,LIM nutrient density model ${ }^{(10)}$. LIM stands for nutrients to LIMit in the SAIn,LIM model. The French standards were $3153 \mathrm{mg} / \mathrm{d}$ for $\mathrm{Na}, 22 \mathrm{~g} / \mathrm{d}$ for SFA and $50 \mathrm{~g} / \mathrm{d}$ for added sugars, based on a standard $8368 \mathrm{~kJ} / \mathrm{d}(2000$ $\mathrm{kcal} / \mathrm{d}$ ) diet. The previously developed and validated LIM score was the mean of \% DV for SFA, added sugar and $\mathrm{Na}$, with all DV calculated per $100 \mathrm{~g}$. The algorithms for the LIM subscore had been published before ${ }^{(10,13)}$.

In past studies, LIM has been expressed per $100 \mathrm{~g}^{(10)}$ and per $418.4 \mathrm{~kJ}(100 \mathrm{kcal})^{(22)}$. The usual serving sizes of milk and dairy products can vary from $30 \mathrm{~g}$ (cheeses) to $200 \mathrm{ml}$ (fluid milk). Nutrient profiling methods based on $100 \mathrm{~g}$ have had difficulty in accommodating diverse serving sizes ${ }^{(11)}$. LIM values were therefore also calculated per serving.

The energy, monetary and LIM costs of meeting $15 \%$ daily value for calcium

All calculations used \% DV based on the French reference for daily intakes ${ }^{(21)}$. Given that French standards for $\mathrm{Ca}$ are set at $800 \mathrm{mg} / \mathrm{d}$, all calculations were based on $15 \% \mathrm{DV}$, equivalent to $120 \mathrm{mg} \mathrm{Ca}$. The amount of energy (kJ (kcal)), volume (g), nutrients to limit (LIM score) and monetary costs (€) that were associated with the provision of $120 \mathrm{mg}$ Ca per reference amount were calculated for each dairy product.

To calculate LIM scores associated with meeting the $15 \% \mathrm{DV}$ Ca requirement, the weight of product providing $15 \% \mathrm{DV} \mathrm{Ca}$ requirement was calculated first. Then, the LIM score for that weight of product was calculated as follows:

$$
\begin{aligned}
& \operatorname{LIM}(15 \% \mathrm{DV} \text { Ca }) \\
& =\frac{\frac{\mathrm{Na}(15 \% \mathrm{DV} \mathrm{Ca})}{3153}+\frac{\operatorname{SFA}(15 \% \mathrm{DV} \mathrm{Ca})}{22}+\frac{\operatorname{added~sugar~}(15 \% \mathrm{DV} \mathrm{Ca})}{50}}{3} \times 100 .
\end{aligned}
$$

A value of 0 indicated that the product provided $15 \% \mathrm{DV} \mathrm{Ca}$ and no nutrients to limit, whereas a value of 100 indicated that the product supplied $15 \% \mathrm{DV} \mathrm{Ca}$ as well as the maximum recommended amount of nutrients per limit. A value of 15 indicated that the product provides as much $\mathrm{Ca}$ as nutrients to limit.

To identify best sources of $\mathrm{Ca}$ at the lowest cost, we used a novel value metric that combined monetary cost and the LIM score: price $(15 \% \mathrm{DV} \mathrm{Ca}) \times \mathrm{LIM}(15 \% \mathrm{DV} \mathrm{Ca})$. Lower scores 
identified those dairy products that met $15 \%$ DV for Ca at low cost and had the lowest LIM score.

\section{Statistical analyses}

All analyses were performed using the Statistical Package for the Social Sciences version 11.0. Comparisons between means using one-way ANOVA were the principal analyses performed. An $\alpha$ level of 0.05 was used to determine statistical significance.

\section{Results}

\section{Cluster analyses to identify twenty-one product categories}

The four major groups of dairy products - milks, fermented milks, desserts and cheeses - vary greatly in nutrient composition. Although fluid milks are comparable in terms of energy and $\mathrm{Ca}$ content, fermented milks and cheeses most definitely are not. Greek yogurts contain more protein but also more fat than does regular yogurts and tend to be classed with desserts.

Cluster analyses, conducted within each of the four major dairy groups, were used to create meaningful product categories on the basis of nutrient composition. The clustering variables - energy, SFA, added sugars and $\mathrm{Na}$ - were expressed per $100 \mathrm{~g}$ product or in amounts associated with $15 \%$ DV for $\mathrm{Ca}$. As noted above, SFA, added sugar and Na constitute the LIM component of the SAIN,LIM nutrient profiling model (10). The method used was hierarchical clustering using Ward's criteria for Euclidean distances between items. Dendrograms were used to assign items into a variable number of clusters per major dairy group, for a total of twenty-one categories in all. As shown in Table 1, milks were divided into skimmed, low-fat, whole and flavoured milks, an assignment in line with industry standards. Fermented milks were divided into categories corresponding to sweetened yogurts (solid and beverage forms), plain yogurts, light yogurts and fortified yogurt beverages, also in line with industry standards. Cheeses were subdivided into eight categories. Table 1 shows the twenty-one categories and lists key examples within each.

\section{Energy and nutrient profiles by food group and category}

Table 2 shows the energy and nutrient profiles for the twentyone categories, along with cost in euros, calculated per $100 \mathrm{~g}$ reference amount. Milks, including flavoured milks, had the lowest energy density, the lowest LIM scores and the lowest $€$ cost (all $P<0 \cdot 001$ ). Fresh dairy products (yogurts) came next, followed by light dairy desserts and plain creamy dairy products. Cheeses had the highest Ca content per $100 \mathrm{~g}$ but were also associated with the highest energy density, higher monetary cost (€) and higher LIM scores, all calculated per $100 \mathrm{~g}$.

The amounts of Ca provided by the twenty-one categories of dairy products were highly variable, ranging almost 20-fold, from $56 \mathrm{mg} / 100 \mathrm{~g}$ (soft cheese) to $1026 \mathrm{mg} / 100 \mathrm{~g}$ (Emmenthal). The amount of Ca provided by fluid milk and yogurt was in the order of $120 \mathrm{mg} / 100 \mathrm{~g}$.

Energy density of milk and dairy products varied 10-fold from $142.3 \mathrm{~kJ} / 100 \mathrm{~g}(34 \mathrm{kcal} / 100 \mathrm{~g})$ for skimmed milk to $1560 \cdot 6 \mathrm{~kJ} /$ $100 \mathrm{~g}(373 \mathrm{kcal} / 100 \mathrm{~g})$ for hard cheese. Cost per $100 \mathrm{~g}$ varied $>10$-fold, from 0.10 euros/100 g for skimmed milk to 1.39 euros/100 g for goat cheese. LIM scores, tracking nutrients to limit, varied from a very favourable 0.7 (skimmed milk) to a less favourable 41.0 (soft cheese). As demonstrated in Table 2, dairy products, milk, yogurts and cheese were extremely heterogeneous with respect to Ca content, energy density and cost $(€)$.

Milks and dairy products were also heterogeneous in terms of recommended servings, which varied from $30 \mathrm{~g}$ to $200 \mathrm{ml}$. Table 3 shows the energy and nutrient profiles per serving for the four groups and the twenty-one categories. There were still significant differences in Ca content per serving across groups. Milks and fresh dairy products provided larger amounts of $\mathrm{Ca}$

Table 1. Milks and dairy products ( $n$ 837) aggregated to four major dairy food groups and twenty-one product categories

\begin{tabular}{|c|c|c|c|}
\hline Food groups & Category names & $n$ & Category examples \\
\hline \multirow[t]{4}{*}{ Milks } & Milks, flavoured & 11 & Chocolate milk, strawberry milk \\
\hline & Milks, full fat & 26 & Full-fat (whole) milk \\
\hline & Milks, low fat & 48 & Reduced and low-fat milk (cow, goat) \\
\hline & Milks, skimmed & 16 & Skimmed milk \\
\hline \multirow[t]{5}{*}{ Fermented milks } & Yogurts, sweetened 1 & 119 & Fermented milk, yogurt beverage, Actimel, Yakult \\
\hline & Yogurts, sweetened 2 & 74 & Fruit yogurt, flavoured yogurt, whole or low-fat milk \\
\hline & Yogurts, plain & 39 & Yogurt, plain (unsweetened), low-fat fromage blanc \\
\hline & Yogurts, light & 83 & Yogurt, plain or flavoured, low fat, low sugar \\
\hline & Yogurt beverages, fortified & 11 & Yogurt, fermented milk, fortified, beverage form \\
\hline \multirow[t]{4}{*}{ Dairy desserts } & Mousses and creams & 46 & Chocolate mousse, ice cream, café liégeois \\
\hline & Dairy desserts, creamy, plain & 27 & Greek yogurt, plain; Petit Suisse, plain \\
\hline & Dairy desserts, light & 27 & Dessert, light (with low-energy sweetener) \\
\hline & Crèmes and flans & 62 & Flan, crème caramel, dessert crème (chocolate, coffee, vanilla, caramel) \\
\hline \multirow[t]{8}{*}{ Cheeses } & Soft cheeses & 8 & Double cream cheese, Boursin, Tartare \\
\hline & Cheeses, cream and goat & 39 & Goat cheese (bûches, crottin, frais), cheese spread (à tartiner) \\
\hline & Semi-hard, double cream & 4 & Saint-Félicien, Saint-Marcelin \\
\hline & Semi-hard, creamy & 30 & Brie, Maroilles, Feta, Caprice des Dieux, Port Salut \\
\hline & Blue cheeses, cream cheeses & 33 & Bleu, Roquefort, Gorgonzola, Tomme de Savoie, Vache qui rit \\
\hline & Semi-hard cheeses ('Camembert') & 52 & Camembert, Coulommiers, Pont I'Évèque, Reblochon, Mozzarella \\
\hline & Hard cheeses 1 ('Gouda') & 43 & Edam, Mimolette, Gouda, Ficello, Babybel, Morbier \\
\hline & Hard cheeses 2 ('Gruyère') & 39 & Emmental, Gruyère, Comté, Parmesan \\
\hline
\end{tabular}

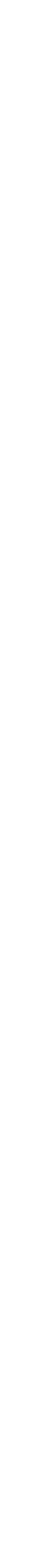


Table 2. Calcium content, energy density, monetary cost and LIM scores per $100 \mathrm{~g}$ for four dairy food groups and twenty-one categories (Mean values and standard deviations)

\begin{tabular}{|c|c|c|c|c|c|c|c|c|c|c|c|}
\hline \multirow[b]{2}{*}{ Names } & \multirow[b]{2}{*}{$n$} & \multicolumn{2}{|c|}{$\mathrm{Ca} / 100 \mathrm{~g}$} & \multicolumn{2}{|c|}{$\mathrm{kJ} / 100 \mathrm{~g}$} & \multicolumn{2}{|c|}{$\mathrm{kcal} / 100 \mathrm{~g}$} & \multicolumn{2}{|c|}{$€ / 100 \mathrm{~g}$} & \multicolumn{2}{|c|}{$\mathrm{LIM} / 100 \mathrm{~g}$} \\
\hline & & Mean & SD & Mean & SD & Mean & SD & Mean & SD & Mean & SD \\
\hline Milks & 101 & 118 & 8 & 213 & 46 & 51 & 11 & 0.11 & 0.04 & $2 \cdot 6$ & 1.4 \\
\hline Milks, flavoured & 11 & 102 & 17 & 267 & 25 & 64 & 6 & 0.18 & 0.06 & $5 \cdot 1$ & 0.8 \\
\hline Milks, full fat & 26 & 120 & 0 & 267 & 4 & 64 & 1 & 0.11 & 0.03 & 3.8 & 0.1 \\
\hline Milks, low fat & 48 & 120 & 0 & 192 & 8 & 46 & 2 & 0.10 & 0.03 & $2 \cdot 0$ & 0.2 \\
\hline Milks, skimmed & 16 & 120 & 0 & 142 & 8 & 34 & 2 & 0.10 & 0.03 & 0.7 & 0.2 \\
\hline Fermented milks (yogurts) & 326 & 127 & 25 & 317 & 92 & 76 & 22 & 0.25 & 0.10 & $5 \cdot 7$ & 3.2 \\
\hline Yogurts, sweetened 1 & 119 & 119 & 9 & 364 & 50 & 87 & 12 & 0.27 & 0.13 & 7.5 & $1 \cdot 1$ \\
\hline Yogurts, sweetened 2 & 74 & 115 & 10 & 405 & 37 & 97 & 9 & 0.25 & 0.08 & 9.0 & 1.2 \\
\hline Yogurts, plain & 39 & 122 & 13 & 292 & 33 & 70 & 8 & 0.21 & 0.04 & 3.8 & 0.4 \\
\hline Yogurts, light & 83 & 135 & 14 & 188 & 33 & 45 & 8 & 0.25 & 0.11 & 1.1 & 0.8 \\
\hline Yogurt beverages, fortified & 11 & 236 & 33 & 33 & 58 & 78 & 14 & 0.36 & 0.08 & 5.9 & $2 \cdot 5$ \\
\hline Dairy desserts & 162 & 112 & 20 & 510 & 125 & 122 & 30 & 0.30 & 0.11 & $11 \cdot 1$ & 3.9 \\
\hline Mousses and creams & 46 & 95 & 14 & 635 & 100 & 152 & 24 & 0.38 & 0.09 & $15 \cdot 1$ & 3.4 \\
\hline Dairy desserts, creamy, plain & 27 & 118 & 14 & 502 & 58 & 120 & 14 & 0.30 & 0.10 & 9.5 & 1.5 \\
\hline Dairy desserts, light & 27 & 139 & 19 & 334 & 79 & 80 & 19 & 0.35 & 0.09 & $5 \cdot 8$ & $2 \cdot 5$ \\
\hline Crèmes and flans & 62 & 111 & 10 & 493 & 62 & 118 & 15 & 0.22 & 0.08 & $11 \cdot 1$ & 1.8 \\
\hline Cheeses & 248 & 537 & 314 & 1313 & 276 & 314 & 66 & $1 \cdot 11$ & 0.52 & $32 \cdot 0$ & $7 \cdot 1$ \\
\hline Soft cheeses & 8 & 56 & 5 & 1502 & 213 & 359 & 51 & 0.95 & 0.18 & 41.0 & 5.7 \\
\hline Cheeses, cream and goat & 39 & 114 & 22 & 1163 & 234 & 278 & 56 & 1.39 & 0.77 & $29 \cdot 7$ & $6 \cdot 0$ \\
\hline Semi-hard, double cream & 4 & 98 & 10 & 1025 & 79 & 245 & 19 & 1.31 & 0.35 & $36 \cdot 4$ & $2 \cdot 8$ \\
\hline Semi-hard, creamy & 30 & 306 & 61 & 1159 & 301 & 277 & 72 & 0.91 & 0.29 & 31.4 & $9 \cdot 1$ \\
\hline Blue cheeses, cream cheeses & 33 & 619 & 40 & 1334 & 251 & 319 & 60 & 1.09 & 0.50 & 34.0 & 7.6 \\
\hline Semi-hard cheeses (Camembert) & 52 & 469 & 33 & 1167 & 221 & 279 & 53 & 0.84 & 0.34 & $28 \cdot 1$ & 6.4 \\
\hline Hard cheeses 1 (Gouda) & 43 & 788 & 48 & 1489 & 171 & 356 & 41 & 1.20 & 0.42 & 35.0 & $5 \cdot 2$ \\
\hline Hard cheeses 2 (Gruyère) & 39 & 1026 & 101 & 1560 & 184 & 373 & 44 & 1.28 & 0.57 & 32.6 & $5 \cdot 2$ \\
\hline One-way ANOVA by food group & & $P<0$. & & $P<0$. & & $P<0.0$ & & $P<0.001$ & & $P<0.001$ & \\
\hline
\end{tabular}


Table 3. Calcium content, energy, monetary cost and the LIM scores per recommended serving for four dairy food groups and twenty-one categories (Mean values and standard deviations)

\begin{tabular}{|c|c|c|c|c|c|c|c|c|c|c|c|}
\hline \multirow[b]{2}{*}{ Names } & \multirow[b]{2}{*}{$n$} & \multicolumn{2}{|c|}{$\mathrm{Ca} /$ serving } & \multicolumn{2}{|c|}{$\mathrm{kJ} /$ serving } & \multicolumn{2}{|c|}{$\mathrm{kcal} /$ serving } & \multicolumn{2}{|c|}{$€ /$ serving } & \multicolumn{2}{|c|}{ LIM/serving } \\
\hline & & Mean & SD & Mean & SD & Mean & SD & Mean & SD & Mean & SD \\
\hline Milks & 101 & 236 & 16 & 422 & 96 & 101 & 23 & 0.23 & 0.09 & $5 \cdot 2$ & $2 \cdot 8$ \\
\hline Milks, flavoured & 11 & 204 & 34 & 535 & 50 & 128 & 12 & 0.36 & 0.13 & $10 \cdot 3$ & 1.6 \\
\hline Milks, full fat & 26 & 240 & 0 & 539 & 8 & 129 & 2 & 0.23 & 0.06 & 7.7 & 0.2 \\
\hline Milks, low fat & 48 & 240 & 4 & 384 & 20 & 92 & 5 & 0.20 & 0.07 & 4.0 & 0.4 \\
\hline Milks, skimmed & 16 & 240 & 0 & 280 & 16 & 67 & 4 & 0.20 & 0.06 & $1 \cdot 3$ & 0.4 \\
\hline Fermented milks (yogurts) & 326 & 158 & 31 & 397 & 117 & 95 & 28 & 0.32 & 0.14 & $7 \cdot 1$ & 4.1 \\
\hline Yogurts, sweetened 1 & 119 & 149 & 11 & 456 & 66 & 109 & 16 & 0.34 & 0.16 & $9 \cdot 3$ & 1.4 \\
\hline Yogurts, sweetened 2 & 74 & 143 & 12 & 506 & 46 & 121 & 11 & 0.31 & 0.10 & $11 \cdot 3$ & 1.5 \\
\hline Yogurts, plain & 39 & 152 & 16 & 368 & 46 & 88 & 11 & 0.26 & 0.05 & 4.8 & 0.5 \\
\hline Yogurts, light & 83 & 169 & 17 & 234 & 41 & 56 & 10 & 0.31 & 0.13 & 1.4 & 0.9 \\
\hline Yogurt beverages, fortified & 11 & 295 & 42 & 405 & 71 & 97 & 17 & 0.44 & 0.10 & $7 \cdot 3$ & $3 \cdot 1$ \\
\hline Dairy desserts & 162 & 140 & 25 & 636 & 159 & 152 & 38 & 0.38 & 0.14 & 13.9 & 4.9 \\
\hline Mousses and creams & 46 & 118 & 17 & 799 & 125 & 191 & 30 & 0.48 & 0.12 & $18 \cdot 9$ & $4 \cdot 2$ \\
\hline Dairy desserts, creamy, plain & 27 & 148 & 17 & 627 & 71 & 150 & 17 & 0.38 & 0.12 & $11 \cdot 8$ & 1.9 \\
\hline Dairy desserts, light & 27 & 174 & 24 & 418 & 100 & 100 & 24 & 0.43 & 0.11 & $7 \cdot 2$ & $3 \cdot 1$ \\
\hline Crèmes and flans & 62 & 138 & 13 & 619 & 79 & 148 & 19 & 0.29 & 0.10 & 13.9 & $2 \cdot 2$ \\
\hline Cheeses & 248 & 161 & 63 & 447 & 150 & 107 & 36 & 0.33 & 0.16 & 9.6 & $2 \cdot 1$ \\
\hline Soft cheeses & 8 & 17 & 2 & 451 & 62 & 108 & 15 & 0.29 & 0.06 & $12 \cdot 3$ & $1 \cdot 7$ \\
\hline Cheeses, cream and goat & 39 & 34 & 6 & 351 & 71 & 84 & 17 & 0.42 & 0.23 & 8.9 & 1.8 \\
\hline Semi-hard, double cream & 4 & 29 & 3 & 305 & 25 & 73 & 6 & 0.39 & 0.11 & 10.9 & 0.9 \\
\hline Semi-hard, creamy & 30 & 92 & 18 & 347 & 92 & 83 & 22 & 0.27 & 0.09 & 9.4 & $2 \cdot 7$ \\
\hline Blue cheeses, cream cheeses & 33 & 186 & 12 & 401 & 75 & 96 & 18 & 0.33 & 0.15 & $10 \cdot 2$ & $2 \cdot 3$ \\
\hline Semi-hard cheeses (Camembert) & 52 & 141 & 10 & 351 & 66 & 84 & 16 & 0.25 & 0.10 & 8.4 & 1.9 \\
\hline Hard cheeses 1 (Gouda) & 43 & 236 & 14 & 447 & 50 & 107 & 12 & 0.36 & 0.13 & $10 \cdot 5$ & 1.6 \\
\hline Hard cheeses 2 (Gruyère) & 39 & 308 & 30 & 468 & 54 & 112 & 13 & 0.38 & 0.17 & 9.8 & 1.6 \\
\hline One-way ANOVA by food group & & $P<0.0$ & & $P<0.0$ & & $P<0.0$ & & $P<0.001$ & & $P<0.001$ & \\
\hline
\end{tabular}


per serving than did dairy desserts and most cheeses. Although milks and fresh dairy products provided $140-240 \mathrm{mg}$ of $\mathrm{Ca}$ per servings, cheeses remained a very heterogeneous group. The monetary cost per serving was lower for milk group than for the cheese group, and the associated LIM scores were lower as well.

\section{Meeting calcium requirements at low cost}

The new metrics aimed to identify those dairy categories that provided $120 \mathrm{mg} \mathrm{Ca}$ per reference amount (serving) without excessive energy or nutrients to limit and at low monetary cost. Table 4 shows, for different groups and categories of dairy products, the weight of product (g), energy (kJ (kcal)), monetary cost (euros) and LIM scores that were associated, respectively, with the provision of $120 \mathrm{mg}$ of $\mathrm{Ca}$ per serving.

First, the amount of energy associated with the provision of $120 \mathrm{mg}$ Ca was significantly lower for fresh dairy products fluid milks and yogurts - as compared with cheeses or dairy desserts $(P<0 \cdot 001)$. However, given that the energy density of cheeses greatly exceeds the energy density of milk and yogurt, some cheeses were able to provide $\mathrm{Ca}$ in a relatively small portion. Table 4 shows the weight of products $(\mathrm{g})$ associated with $120 \mathrm{mg} \mathrm{Ca}$. Ca-rich products such as hard and semi-hard cheeses, followed by fortified yogurt, provided $\mathrm{Ca}$ in small portions. By contrast, soft and cream cheeses, mousses and creams required a large volume to provide $120 \mathrm{mg} \mathrm{Ca}$.

As shown in Table 4, fresh dairy products, especially plain milks, were the most affordable $\mathrm{Ca}$ source. Even though cheeses as a group were more expensive, some Ca-rich hard cheeses were an affordable Ca source. Also shown are the LIM scores for each food group and category. LIM scores per $15 \%$ DV Ca were significantly lower for fresh dairy products, fluid milks and yogurts as compared with cheeses or to dairy desserts $(P<0 \cdot 001)$. The lowest LIM scores per $15 \% \mathrm{DV}$ Ca were observed for skimmed milk and light yogurts, and the highest LIM scores were observed for double cream and cream cheeses. The LIM $\times €$ price index - a novel measure - was likewise most favourable for fresh dairy products, milks and yogurts than for desserts or cheeses. The combined LIM price index was obtained by multiplying LIM score for each product by its monetary cost in euros.

The cheeses' category was very heterogeneous in terms of energy density, Ca content and cost. Ca-rich hard cheeses (Comté, Gruyère, Gouda), semi-hard cheeses (Camembert) and blue cheeses (Roquefort) followed fresh dairy products in supplying $\mathrm{Ca}$ at low LIM and monetary cost. All cross-group comparisons based on one-way ANOVA were significant $(P<0 \cdot 001)$

The interrelations between $\mathrm{Ca}$ content per serving and the cost in energy and LIM scores are illustrated further in Fig. 1. Ca content per serving is indicated on the $y$-axis and the $15 \% \mathrm{DV}$ (120 mg) is indicated by a broken line. The size of each bubble reflected the cost in euros associated with the provision of $120 \mathrm{mg}$ of $\mathrm{Ca}$.

Fig. 1(a) shows the relation between the amount of $\mathrm{Ca}$ per serving and energy cost associated with $15 \%$ DV Ca $(\mathrm{kJ}$ $502.1 \mathrm{mg}$ ( $\mathrm{kcal} / 120 \mathrm{mg}$ ) Ca). It can be seen that most dairy products provided more (or much more) than $120 \mathrm{mg} \mathrm{Ca}$ per serving. Fresh dairy products and hard cheeses provided $\mathrm{Ca}$ at the lowest energy cost.

Fig. 1(b) shows LIM scores associated with $15 \%$ DV Ca. Again, milks, yogurts and some cheeses provided Ca at low LIM cost. Product amounts, shown in Fig. 1(c) show that the most Ca-rich cheeses, along with flavoured yogurts, provided $\mathrm{Ca}$ within a relatively compact product volume.

\section{Discussion}

The present analyses of a large number of dairy products in France showed that the French $\mathrm{Ca}$ requirements ${ }^{(21)}$ could be met by a wide variety of dairy products at an affordable cost and without excessive energy or nutrients to limit (LIM). Dairy products are the principal source of dietary $\mathrm{Ca}$ in France ${ }^{(23)}$ and in the $\mathrm{USA}^{(7)}$. Fluid milks and yogurt had three advantages: (1) low Ca price index; (2) low energy density; and (3) low amount of energy associated with meeting Ca requirements. Interestingly, some cheeses had favourable price index values but were associated with higher energy density.

Foods and food groups that provide relatively more nutrients than energy can be classified as nutrient rich $^{(7,23)}$. For example, although milk and milk products contributed only $10-13 \%$ of dietary energy to the American diet, this food group was among the main dietary sources of several key micronutrients ${ }^{(7)}$. Although some foods may contribute more energy than nutrients, milk and dairy products tend to provide more nutrients than energy. Being able to separate nutrient-rich from energydense foods is one important aspect of nutrition education and guidance and being able to identify affordable NRF is another.

New value metrics have helped to identify foods that were affordable, accessible and nutrient rich $^{(13)}$. These metrics, developed for selected foods in the US and in the French food supply, were based on calculations of nutrients per energy and nutrients per unit cost ${ }^{(9,24)}$. We have now adapted these metrics to analyses of milk and dairy products in France. As might be expected, milks and dairy products - including cheeses - were very heterogeneous. Although all dairy products contained Ca, the Ca content varied sharply across product categories as did the associated energy and some nutrients of public health concern. Plain fluid milks provided $120 \mathrm{mg} \mathrm{Ca}$ at the lowest price and at the lowest energy and LIM cost. Fresh plain and 'light' yogurts and fermented milks were next, followed by sweetened yogurts and flavoured milks, all provided at relatively low cost. Light dairy desserts had low energy and low LIM scores but were more expensive. Cheeses were a very heterogeneous category. Ca-rich hard cheeses were comparable to plain yogurts in terms of Ca costs. Semi-hard and blue cheeses were comparable on most metrics to sweetened yogurts and flavoured milks. However, double cream and soft cheeses, along with goat cheeses, had a relatively low $\mathrm{Ca}$ content per serving and were less-than-optimal Ca sources.

Nutrient profiling techniques can help consumers identify NRF in relation to cost, can help them make better food choices and improve the quality of their diets. The joining of the nutrient composition and price databases opens the door to new studies on foods' nutritive value in relation to their monetary cost. 
Table 4. Weight, energy, monetary cost and the LIM scores associated with meeting $15 \%$ daily values (DV) calcium for four dairy food groups and twenty-one categories (Means values and standard deviations)

\begin{tabular}{|c|c|c|c|c|c|c|c|c|c|c|c|c|c|}
\hline \multirow[b]{2}{*}{ Names } & \multirow[b]{2}{*}{$n$} & \multicolumn{2}{|c|}{ Weight $(\mathrm{g}) / 15 \% \mathrm{DV} \mathrm{Ca}$} & \multicolumn{2}{|c|}{$\mathrm{kJ} / 15 \% \mathrm{DV} \mathrm{Ca}$} & \multicolumn{2}{|c|}{$\mathrm{kcal} / 15 \% \mathrm{DV} \mathrm{Ca}$} & \multicolumn{2}{|c|}{$€$ Cost $/ 15 \%$ DV Ca } & \multicolumn{2}{|c|}{$\mathrm{LIM} / 15 \% \mathrm{DV} \mathrm{Ca}$} & \multicolumn{2}{|c|}{$\mathrm{LIM} \times € / 15 \% \mathrm{DV} \mathrm{Ca}$} \\
\hline & & Mean & SD & Mean & SD & Mean & SD & Mean & SD & Mean & SD & Mean & SD \\
\hline Milks & 101 & 102 & 9 & 217 & 54 & 52 & 13 & 0.12 & 0.05 & $2 \cdot 72$ & 1.64 & 0.37 & 0.43 \\
\hline Milks, flavoured & 11 & 120 & 19 & 317 & 33 & 76 & 8 & 0.22 & 0.07 & $6 \cdot 17$ & $1 \cdot 13$ & 1.39 & 0.59 \\
\hline Milks, full fat & 26 & 100 & 0 & 267 & 4 & 64 & 1 & 0.11 & 0.03 & 3.84 & 0.11 & 0.44 & 0.11 \\
\hline Milks, low fat & 48 & 100 & 2 & 192 & 8 & 46 & 2 & 0.10 & 0.03 & 2.00 & 0.14 & 0.20 & 0.06 \\
\hline Milks, skimmed & 16 & 100 & 0 & 142 & 8 & 34 & 2 & $0 \cdot 10$ & 0.03 & 0.65 & 0.20 & 0.07 & 0.04 \\
\hline Fermented milks (yogurts) & 326 & 97 & 13 & 313 & 112 & 75 & 27 & 0.25 & 0.11 & $5 \cdot 69$ & 3.45 & 1.50 & 1.26 \\
\hline Yogurts, sweetened 1 & 119 & 101 & 7 & 368 & 54 & 88 & 13 & 0.27 & 0.13 & 7.51 & 1.09 & 2.08 & $1 \cdot 12$ \\
\hline Yogurts, sweetened 2 & 74 & 105 & 10 & 426 & 66 & 102 & 16 & 0.26 & 0.09 & 9.48 & 1.32 & $2 \cdot 54$ & 1.02 \\
\hline Yogurts, plain & 39 & 100 & 10 & 292 & 54 & 70 & 13 & 0.21 & 0.05 & 3.80 & 0.57 & 0.79 & 0.28 \\
\hline Yogurts, light & 83 & 90 & 9 & 167 & 33 & 40 & 8 & 0.22 & $0 \cdot 10$ & 0.97 & 0.67 & 0.22 & 0.21 \\
\hline Yogurt beverages, fortified & 11 & 52 & 7 & 167 & 25 & 40 & 6 & 0.18 & 0.04 & 2.89 & 1.11 & 0.53 & 0.25 \\
\hline Dairy desserts & 162 & 110 & 19 & 573 & 200 & 137 & 48 & 0.34 & 0.15 & 12.57 & 5.71 & 4.67 & 4.00 \\
\hline Mousses and creams & 46 & 129 & 17 & 815 & 138 & 195 & 33 & 0.49 & 0.15 & 19.31 & 4.56 & $9 \cdot 56$ & 4.25 \\
\hline Dairy desserts, creamy, plain & 27 & 103 & 12 & 518 & 104 & 124 & 25 & 0.31 & 0.11 & 9.76 & 2.09 & $3 \cdot 19$ & 1.62 \\
\hline Dairy desserts, light & 27 & 87 & 10 & 288 & 66 & 69 & 16 & 0.30 & 0.09 & 5.03 & $2 \cdot 24$ & 1.58 & 1.08 \\
\hline Crèmes and flans & 62 & 109 & 11 & 535 & 54 & 128 & 13 & 0.25 & 0.08 & 12.08 & 1.92 & 3.04 & 1.20 \\
\hline Cheeses & 248 & 43 & 47 & 539 & 627 & 129 & 150 & 0.49 & 0.62 & 13.97 & $17 \cdot 25$ & $15 \cdot 33$ & $36 \cdot 0$ \\
\hline Soft cheeses & 8 & 215 & 21 & 3175 & 368 & 767 & 88 & 2.05 & 0.37 & 87.27 & 7.42 & $178 \cdot 0$ & 28.9 \\
\hline Cheeses, cream and goat & 39 & 108 & 19 & 1209 & 217 & 296 & 52 & 1.43 & 0.68 & 31.83 & 6.84 & $45 \cdot 15$ & 22.05 \\
\hline Semi-hard, double cream & 4 & 123 & 13 & 1263 & 171 & 302 & 41 & 1.59 & 0.31 & 44.70 & 3.26 & $70 \cdot 60$ & 8.86 \\
\hline Semi-hard, creamy & 30 & 41 & 10 & 460 & 121 & 110 & 29 & 0.37 & 0.14 & 12.35 & 3.71 & 4.71 & 2.65 \\
\hline Blue cheeses, cream cheeses & 33 & 19 & 1 & 259 & 50 & 62 & 12 & 0.21 & 0.10 & 6.62 & 1.59 & 1.44 & 0.81 \\
\hline Semi-hard cheeses (Camembert) & 52 & 26 & 2 & 301 & 62 & 72 & 15 & 0.21 & 0.09 & $7 \cdot 24$ & 1.74 & 1.58 & 0.80 \\
\hline Hard cheeses 1 (Gouda) & 43 & 15 & 1 & 230 & 33 & 55 & 8 & 0.18 & 0.07 & $5 \cdot 36$ & 0.94 & 1.00 & 0.42 \\
\hline Hard cheeses 2 (Gruyère) & 39 & 12 & 1 & 184 & 29 & 44 & 7 & 0.15 & 0.05 & 3.83 & 0.65 & 0.56 & 0.21 \\
\hline One-way ANOVA by food group & & $P<0.00$ & & $P<0$. & & $P<0.0$ & & $P<0.001$ & & $P<0.001$ & & $P<0.001$ & \\
\hline
\end{tabular}


(a)

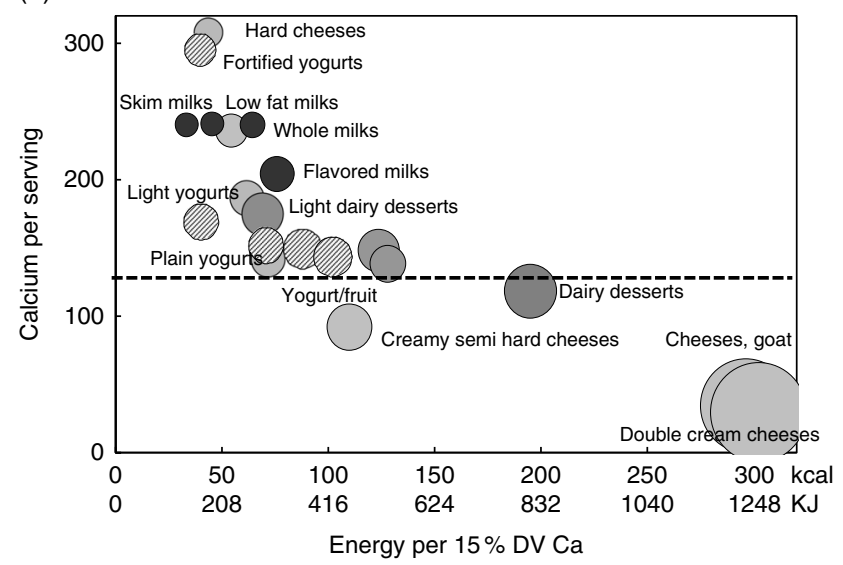

(b)

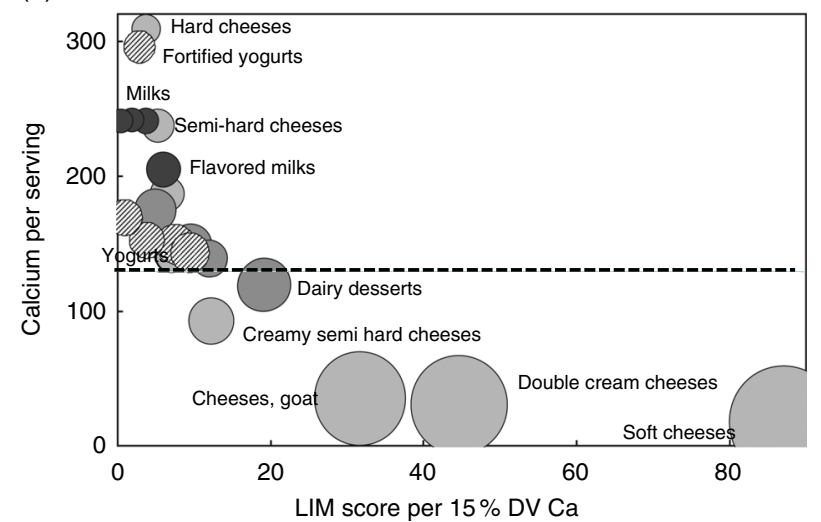

(c)

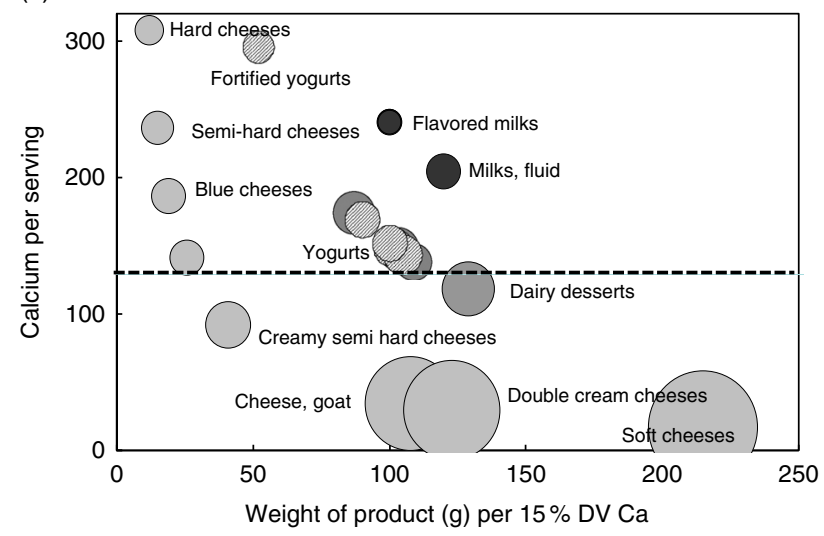

Fig. 1. The relation between mean amount of calcium per serving ( $y$-axis) and (a) mean amount of energy ( $\mathrm{kJ}(\mathrm{kcal})$ ) associated with obtaining $15 \%$ daily value (DV) calcium, (b) LIM score associated with obtaining $15 \%$ DV calcium and (c) mean gram weight of products associated with obtaining $15 \%$ DV calcium. Size of the bubble denotes cost in euros associated with obtaining $15 \%$ DV calcium. The data are for twenty-one product categories in four major groups: milks $(\bigcirc)$, yogurts $(\oslash)$, desserts $(\bigcirc)$ and cheeses $(\bigcirc)$.

Better measures of nutrient affordability can be created by calculating nutrients per unit cost. Ca density per serving multiplied by food prices per serving was the basis of the Ca-affordability score.

The present model examined the cost associated with meeting Ca guidelines, taking into account the foods' content of SFA, added sugar and $\mathrm{Na}$. To be truly useful, such models need to take into account food prices and the frequency of consumption.

Consumers select foods on the basis of taste, cost, convenience and nutritional value. Low-income consumers faced with budgetary constraints may opt for lower-cost foods of high energy density but potentially lower nutritional value. The present calculations, thus far limited in scope to a selected number of food subgroups, illustrate how the econometric approach to nutrient profiling can help identify affordable NRF within each food group.

\section{Conclusions}

Clearly, Ca requirements from dairy products can be met at very different levels of energy and cost. The wide range of dairy options ensures that the $\mathrm{Ca}$ requirements (15\% DV for Ca per serving) are met, while minimising energy, added sugar, SFA and $\mathrm{Na}$. New affordability metrics can help consumers identify those dairy foods that provide optimal nutrition and the lowest cost. Joining nutrient density profiling with the economics of food-choice behaviour is a relatively novel area of research. More work is needed to develop appropriate metrics to identify affordable NRF and their likely adoption by the public.

\section{Acknowledgements}

This study was funded by Danone Research, France. A. D. has received grants, honoraria and consulting fees from numerous food, beverage and ingredient companies and other commercial and nonprofit entities with an interest in the nutrient density of foods. The University of Washington receives research funding from public and private sectors.

A. D. conceptualised the study, drafted the manuscript and had primary responsibility for the final content. W. T. assisted drafting tables and figures. R. B. reviewed databases and assisted in necessary calculations. All the authors read and approved the final manuscript.

W. T. and R. B. have no conflicts of interest.

\section{References}

1. US Department of Agriculture \& US Department of Health and Human Services (2010) Dietary Guidelines for Americans. Washington, DC: US Government Printing Office.

2. French Agency for Food, Environmental and Occupational Health \& Safety (2013) Population reference intakes. http:// www.anses.fr/en/content/population-reference-intakes (accessed February 2015).

3. Clerfeuille E, Maillot M, Verger EO, et al. (2013) Dairy products: how they fit in nutritionally adequate diets. $J$ Acad Nutr Diet 113, 950-956.

4. Astrup A (2014) Yogurt and dairy product consumption to prevent cardiometabolic diseases: epidemiologic and experimental studies. Am J Clin Nutr 99, 1235s-1242s.

5. Rizzoli R (2014) Dairy products, yogurts, and bone health. $A m$ J Clin Nutr 99, 1256s-1262s.

6. Wielgos B, Leszczynska T, Kopec A, et al. (2012) Assessment of intake of minerals with daily diets by children aged $10-12$ years from Malopolska region. Rocz Panstw Zakl Hig 63, 329-337. 
7. Drewnowski A (2011) The contribution of milk and milk products to micronutrient density and affordability of the US diet. J Am Coll Nutr 30, 422s-428s.

8. Fulgoni VL, 3rd, Keast DR, Auestad N, et al. (2011) Nutrients from dairy foods are difficult to replace in diets of Americans: food pattern modeling and an analyses of the National Health and Nutrition Examination Survey 2003-2006. Nutr Res 31, 759-765.

9. Drewnowski A (2010) The cost of US foods as related to their nutritive value. Am J Clin Nutr 92, 1181-1188.

10. Darmon N, Vieux F, Maillot M, et al. (2009) Nutrient profiles discriminate between foods according to their contribution to nutritionally adequate diets: a validation study using linear programming and the SAIN,LIM system. Am J Clin Nutr 89, 1227-1236.

11. Drewnowski A \& Fulgoni V III (2008) Nutrient profiling of foods: creating a nutrient-rich food index. Nutr Rev 66, 23-39.

12. Fulgoni VL, 3rd, Keast DR \& Drewnowski A (2009) Development and validation of the nutrient-rich foods index: a tool to measure nutritional quality of foods. J Nutr 139, 1549-1554.

13. Drewnowski A (2013) New metrics of affordable nutrition: which vegetables provide most nutrients for least cost? J Acad Nutr Diet 113, 1182-1187.

14. Drewnowski A \& Rehm CD (2013) Vegetable cost metrics show that potatoes and beans provide most nutrients per penny. PLOS ONE 8, e63277.

15. Drewnowski A (2010) The Nutrient Rich Foods Index helps to identify healthy, affordable foods. Am J Clin Nutr 91, 1095s-1101s

16. Centre National Interprofessionnel de l'Économie Laitière (French National Interprofessional Center for the Dairy Economy) (2013) La filière laitière française. http://www.maison-dulait.com/fr/les-organisations/cniel (accessed February 2015).
17. Centre National Interprofessionnel de l'Économie Laitière (French National Interprofessional Center for the Dairy Economy) (2008) La consommation de produits laitiers en France (The consumption of dairy products in France). http://www.sante.gouv.fr/IMG/pdf/Presentation_lipides_produits_laitiers_ATLA.pdf (accessed February 2015).

18. French Agency for Food, Environmental and Occupational Health \& Safety (2012) Table-CIQUAL 2012. http://pro.anses. $\mathrm{fr} /$ TableCIQUAL/index.htm (accessed June 2015).

19. Les Produits Laitiers (2015) Alimentation et santé. http://www. produits-laitiers.com/tous-les-produits-laitiers-apportent-ducalcium/ (accessed August 2015).

20. United States Food and Drug Administration (2015) Code of Federal Regulations Title 21, vol 2, part 101, food labeling. Reference amounts customarily consumed per eating occasion. http://www.accessdata.fda.gov/scripts/cdrh/ cfdocs/cfcfr/cfrsearch.cfm?fr $=101.12$ (accessed February 2015).

21. Council of the European Community (1990) Directives pertaining to the labeling of food products (in French). http:// eur-lex.europa.eu/LexUriServ/LexUriServ.do?uri=CONSLEG: 1990L0496:20081211:FR:PDF (accessed June 2015).

22. Drewnowski A, Maillot M \& Darmon N (2009) Should nutrient profiles be based on $100 \mathrm{~g}, 100 \mathrm{kcal}$ or serving size? Eur J Clin Nutr 63, 898-904.

23. Coudray B (2011) The contribution of dairy products to micronutrient intakes in France. $J$ Am Coll Nutr 30, 410s-414s.

24. Darmon N, Darmon M, Maillot M, et al. (2005) A nutrient density standard for vegetables and fruits: nutrients per calorie and nutrients per unit cost. J Am Diet Assoc 105, 1881-1887. 